\title{
Buzz: Face-To-Face Contact and the Urban Economy
}

Michael Storper and Anthony J. Venables

December 2003 


\begin{abstract}
This paper argues that existing models of urban concentrations are incomplete unless grounded in the most fundamental aspect of proximity; face-to-face contact. Face-to-face contact has four main features; it is an efficient communication technology; it can help solve incentive problems; it can facilitate socialization and learning; and it provides psychological motivation. We discuss each of these features in turn, and develop formal economic models of two of them. Face-to-face is particularly important in environments where information is imperfect, rapidly changing, and not easily codified, key features of many creative activities.
\end{abstract}

Keywords: Agglomeration, clustering, urban economics, face-to-face.

JEL classification: R1

The Centre for Economic Performance is financed by the Economic and Social Research Council. This paper was produced as part of the Centre's Globalisation Programme.

\title{
Acknowledgements
}

Earlier versions of this paper were presented at the International Seminar on Economy and Space, Faculty of Economics, Federal University of Minas Gerais (FACE/UFMG), Centre for Regional Development and Planning (CEDEPLAR), Ouro Preto, Minas Gerais, Brazil, December 6-7, 2001; as keynote address to the Third International Congress on the Dynamics of Proximity, Paris, December 2001; to the Center for Globalization and Policy Studies, UCLA, March 2002; and to the DRUID Summer Conference, June 2003. Thanks to anonymous referees and to editors of this the Journal of Economic Geography for valuable comments.

Michael Storper: Professor of Economic Geography at the London School of Economics (m.storper@1se.ac.uk); Institute of Political Studies (IEP, Sciences-Po, Paris).

Anthony J. Venables: Director, Globalisation Programme, Centre for Economic Performance, London School of Economics; Professor of International Economics, LSE (a.j.venables@1se.ac.uk); Research Fellow, Centre for Economic Policy Research, London.

Published by

Centre for Economic Performance

London School of Economics and Political Science

Houghton Street

London WC2A $2 \mathrm{AE}$

All rights reserved. No part of this publication may be reproduced, stored in a retrieval system or transmitted in any form or by any means without the prior permission in writing of the publisher nor be issued to the public or circulated in any form other than that in which it is published.

Requests for permission to reproduce any article or part of the Working Paper should be sent to the editor at the above address.

(C) M. Storper and A. J. Venables, submitted 2003

ISBN 0753016761

Individual copy price: $£ 5$ 


\section{FACE-TO-FACE CONTACT REMAINS IMPORTANT}

Face-to-face contact remains central to coordination of the economy, despite the remarkable reductions in transport costs and the astonishing rise in the complexity and variety of information - verbal, visual and symbolic - which can be communicated near instantly. Over the past quarter century, long-distance business travel has grown faster than output and trade (Hall, 1998). There must be powerful reasons for economic agents to congregate and see each other, given the relatively high pecuniary and opportunity cost of business travel. Forces of urbanization and localization remain strong. For example, the geographical density of employment in many sectors in the US has actually increased in recent years (Kim, 2002). It has also been estimated that, in the US, 380 localized clusters of firms employ $57 \%$ of the total workforce and generate $61 \%$ of the nation's output and fully $78 \%$ of its exports (Rosenfeld, 1996). Other researchers, using more conservative measures, still find that $30 \%$ of the US workforce is accounted for by localized employment clusters (Porter, 2001). Urbanization is continuing apace in developing countries, and many cities in high-income countries are experiencing a resurgence (Scott, 2001).

Three main forces are thought to lie behind the persistence of urbanization and localization: backward and forward linkages of firms, including access to markets; the clustering of workers; and localized interactions which promote technological innovation. We argue in this paper that analysis of these mechanisms is likely to be incomplete unless grounded in the most fundamental aspect of proximity: face-to-face contact (F2F).

To begin with, there is widespread agreement that localized backward and forward linkages, while important in specific cases, can account for only a small part of contemporary urbanization (Gordon and McCann, 2000). More importantly, when such linkages are strongly localized, it is rarely because of high physical transport costs, and frequently because the 
information associated with the physical transaction is costly or difficult to transmit at great distance. Deal-making, evaluation and relationship adjustment are heavily dependent on face-toface contact.

The clustering of workers is considered to be a strong contributor to localization and urbanization, largely because of the increasing demand for specialized skills and more flexible, higher turnover labor markets. Taken together, they place a premium on clustering because employers thereby gain access to a large pool of specialized labor and can avoid hoarding during downturns. Workers gain access to a greater number of potential employers, allowing them to minimize periods of unemployment and make more rapid progression up a career ladder, with greater lifetime learning and wage growth (Rotemberg and Saloner, 2000; Jayet, 1983). Underpinning these dynamics, however, are detailed processes of signaling and screening which occur largely through face-to-face contact, as well as network structures that are constructed through such contact (Granovetter, 1986).

The third group of explanations concern technological innovation. There is fragmentary but fairly convincing evidence that cities are centers of innovation in the production of ideas and knowledge and in their commercialisation (Feldman and Audretsch, 1999; Jaffe, Trachtenberg and Henderson, 1993). The notion frequently adduced to explain these facts is that spatial proximity must somehow improve flows of information upon which innovators depend, creating technological "spillovers". However, the mechanisms underlying these spillovers remain unclear. One avenue of inquiry has to do with the circulation of knowledgeable workers between firms, enhancing the ability of these firms to recombine knowledge, imitate best practices, and otherwise improve their products. For example, in Glaeser's (1999) model of learning, people can absorb knowledge from contact with more skilled individuals in their own industry, and the number of probable contacts an individual makes is an increasing function of city size. Large 
cities therefore facilitate learning, and are particularly attractive for highly-talented young people who have large potential returns from learning. The hypothesis is therefore, that knowledge "rubs off" on people in places such as Silicon Valley or the City of London. But if this is the case, it is through F2F that rubbing off occurs, and we require a theory of the motivations people have for engaging in $\mathrm{F} 2 \mathrm{~F}$.

Jacobs (1969) advanced the idea that cities enjoy an advantage because of their economic and social diversity. This diversity, because it is highly packed into limited space, facilitates haphazard, serendipitous contact among people. Florida (2002), drawing on the classical notions of Simmel and Tönnies (Simmel, 1950), argues that the diversity found in cosmopolitan cities facilitates "creativity" because of the openness of their networks, the liberating force of anonymity and hence resistance to hide-bound tradition. But in none of these formulations can be found a direct explanation of the F2F interaction by which cosmopolitanism and diversity have their positive effects. Nor do these approaches consider the disadvantages of anonymity and large numbers, in the form of the costs to coordination they may generate, or the way in which the economy overcomes these difficulties. ${ }^{1}$

In another vein, Alfred Marshall, one of the main inspirations for contemporary students of the "industrial district", also suggested the importance of direct and unplanned contact between economic agents (Marshall, 1919; Becattini, 2000). Marshall centers on belonging to a specialised producer community which diffuses the "secrets" of industry, not the kind of cosmopolitan and haphazard city life described by Jacobs. Numerous attempts have been made to transform his notion into a theory of the milieux underlying contemporary industrial districts. All beg the question: if agents belong to a mileu, what do their interactions consist of and what

\footnotetext{
${ }^{1}$ Although the classical arguments in sociology were concerned precisely with the negative effects of the modern urban social order in the form of their notion of anomie. While sociology does have a notion of the compensating forms of "social integration" that might aid modern anonymous actors to become part of a society,
} 
are the incentives for undertaking such interactions?

In sum, the various theories of agglomeration and the persistence of cities refer to transactional structures and circumstances that necessitate close contact between persons, and to the various outcomes of proximity between agents - more effective input-output linkages, more effective labor market matching, technological spillovers. However, they do not explain precisely what individuals do in this form of encounter, nor why they do it. These encounters are, of course, face-to-face contacts between economic agents. F2F is thus a missing aspect of mechanisms that are considered to generate agglomeration.

This paper contributes to the understanding of F2F contact. First, we show that F2F has unique behavioral and communicational properties which give it specific advantages as a technology of communication, coordination, and motivation (\$2). We develop two gametheoretic models which illustrate why agents engage in F2F contact and contribute some building blocks of a micro-economic theory of $\mathrm{F} 2 \mathrm{~F}(\S 3)$. We then place these ideas in the wider context of the role of F2F, amongst other mechanisms, in coordinating activity in different areas of the economy (§4). Finally, we offer concluding remarks on the future importance of F2F.

\section{THE SPECIFIC PROPERTIES OF FACE-TO-FACE CONTACT}

In order to consider the possible role of F2F in the economy, its properties as a type of behavior and interaction need to be identified. Table 1 lists four major properties of F2F contact: it is an efficient communication technology; it allows actors to align commitments and thereby reduces incentive problems; it allows screening of agents; and it motivates effort.

it does not ask how actors might "coordinate" in the face of anonymity and large numbers. 
Table 1: FACE-TO-FACE CONTACT

\begin{tabular}{|l|l|l|}
\hline \multicolumn{1}{|c|}{ FUNCTION } & \multicolumn{1}{|c|}{ ADVANTAGE OF F2F } & \multicolumn{1}{c|}{ CONTEXT } \\
\hline $\begin{array}{l}\text { Communication } \\
\text { technology. }\end{array}$ & $\begin{array}{l}\text { High frequency. } \\
\text { Rapid feedback. } \\
\text { Visual and body language cues. }\end{array}$ & $\begin{array}{l}\text { Non-codifiable information. } \\
\text { R\&D. } \\
\text { Teaching. }\end{array}$ \\
\hline $\begin{array}{l}\text { Trust and incentives in } \\
\text { relationships. }\end{array}$ & $\begin{array}{l}\text { Detection of lying. } \\
\text { Co-presence a commitment of } \\
\text { time. }\end{array}$ & Meetings. \\
\hline $\begin{array}{l}\text { Screening and } \\
\text { socializing. }\end{array}$ & $\begin{array}{l}\text { Loss of anonymity. } \\
\text { Judging and being judged. } \\
\text { Acquisition of shared values. }\end{array}$ & $\begin{array}{l}\text { Professional groups } \\
\text { Being 'in the loop'. }\end{array}$ \\
\hline Rush and motivation & Performance as display & Presentations \\
\hline
\end{tabular}

\subsection{F2F contact as a communication technology}

The first row of Table 1 refers to the advantages of $\mathrm{F} 2 \mathrm{~F}$ as a communication technology, particularly when much of the information to be transmitted cannot be codified.

Codifiable information has a stable meaning which is associated in a determinate way with the symbol system in which it is expressed, whether it be linguistic, mathematical, or visual. Such information is cheap to transfer because its underlying symbol systems can be widely disseminated through information infrastructure, sharply reducing the marginal cost of individual messages. Acquiring the symbol system may be expensive or slow (language, mathematical skills, etc), as may be building the transmission system, but using it to communicate information is cheap. Thus, the transmission of codifiable information has strong network externalities, since once the infrastructure is acquired a new user can plug in and access the whole network.

By contrast, uncodifiable information is only loosely related to the symbol system in which it is expressed. This includes much linguistic, words-based expression (the famous distinction between "speech" and "language"), particularly what might be called "complex discourse" (Searle, 1969). For example, one can master the grammar and the syntax of a 
language without understanding its metaphors. This is also true for some mathematically expressed information, and much visual information. If the information is not codifiable, merely acquiring the symbol system or having the physical infrastructure is not enough for the successful transmission of a message. Transmission of uncodifable information may have very limited network externalities, since the successful transmission of the message depends on infrastructure that is largely committed to one specific sender-receiver pair. Bateson (1973) refers to the "analog" quality of tacit knowledge: communication between individuals which requires a kind of parallel processing of the complexities of an issue, as different dimensions of a problem are perceived and understood only in relation to one another.

F2F encounters provide an efficient technology of transaction under these circumstances, by permitting a depth and speed of feedback that is impossible in other forms of communication. As organizational theorists Nitin Nohria and Robert Eccles (1992: 292) point out:

'...relative to electronically-mediated exchange, the structure of face-to-face interaction offers an unusual capacity for interruption, repair, feedback, and learning. In contrast to interactions that are largely sequential, face-to-face interaction makes it possible for two people to be sending and delivering messages simultaneously. The cycle of interruption, feedback and repair possible in face-to-face interaction is so quick that it is virtually instantaneous.'

This echoes the findings of sociologist Goffman (1982) that "a speaker can see how others are responding to her message even before it is done and alter it midstream to elicit a different response."

But it is not just the uncodifiability of much information that makes F2F a superior technology. Communication in an F2F context occurs on many levels at the same time -- verbal, physical, contextual, intentional, and non-intentional. Such multidimensional communication is held by many to be essential to the transmission of complex, tacit knowledge. For example, social psychologists argue that creativity results from several different ways of processing 
information at one time, including not only the standard deductive way but analogical, metaphorical, and parallel methods as well (Bateson 1973; Csikszentmihalyi 1996). These different means of communication are mutually enriching, and lead to connections being made that cannot be had through strictly linear perception and reasoning. An extension of this is that the full benefits of diversity and serendipity are only realized through these multiple levels of communication. Linguists such as Searle (1969) and Austin (1962) develop another aspect of communicational analysis, arguing that "language is behavior" and F2F dialogue is a complex socially-creative activity. In a similar vein, sociologists such as Goffman (1959) and Garfinkel (1987) show that the interaction which comes from co-presence can be likened to being on stage, playing a role, where the visual and corporeal cues are at least as important to knowing what is being "said" as are the words themselves.

\subsection{Trust and incentives in relationships:}

The second row of Table 1 refers to the notion that co-presence may reduce incentive and coordination problems that arise in economic relationships. With tacit knowledge there is always residual uncertainty and hence the need to minimize the incentives for one agent to free ride or manipulate the other. These moral hazards exist when the inherent degree of reliability of a message is low. They can sometimes be reduced through improvements in the transparency or clarity of the information itself or in how well it can be verified. But in other cases they require shaping a relationship between the interested parties. Being close enough literally to touch each other allows visual "contact" and "emotional closeness," the basis for building human relationships.

For example, the contemporary knowledge-based economy involves many projects in which individuals come together to acquire and exchange information. Typically the later stages 
of such a project -- writing the report, executing the transaction, or constructing the investment -involve codifiable information. It is the earlier stages where information is more fluid. Is the project a good idea? Should one approach be followed or another? Answering these questions requires that partners in the project undertake research and share their results. Often neither the inputs nor the outputs of this research are observable. Thus, a partner can conscientiously research the project or simply free-ride, hoping that other members of the team will do the work.

F2F can play important roles in mitigating these incentive and free-rider problems. One reason for this is simply that it is easier to observe and intepret a partner's behavior in an F2F situation. Any message may be understood but not believed. There are strong questions of intentionality at work in communication. Knowing the intentions of another actor enables us to decode the practical consequences of what they are expressing to us (Husserl, 1968). Speech and action are tightly interrelated, but speech does not automatically reveal to us what another person intends to do (Searle, 1969). Humans are very effective at sensing non-verbal messages from one another, particularly about emotions, cooperation, and trustworthiness. Putnam (2000:175) notes that "it seems that the ability to spot non-verbal signs of mendacity offered a significant survival advantage during the course of human evolution." Psychologist Albert Mehrabian (1981:iii) notes that "our facial and vocal expressions, postures, movements and gestures," are crucial; when our words "contradict the messages contained within them, others mistrust what we say -they rely almost completely on what we do."

A second reason is that F2F may promote the development of trust. Trust depends on reputation effects or on multi-layered relations between the parties to a transaction that can create low-cost enforcement opportunities (Gambetta, 1988; Lorenz, 1992). Trust also comes from the fact that partners expend time, money and effort in building a relationship. The time and money costs of co-presence (schmoozing) can be substantial, far outweighing the cost of the message. 
These costs are sunk, so indicate a willingness to embark on a repeated relationship; absent a second date, the value of the first date disappears. However, to create a relationship bond, the costs must be substantial and transparent. E-mail, paradoxically, can be so efficient that it destroys the value of the message. The e-mail medium greatly reduces the cost of sending a message, somewhat reduces the cost of receiving the message, and it makes the costs mostly nontransparent. The low costs and the nontransparency greatly limit the value of the relationship

bond. A return receipt only means that the recipient has opened the message, but the sender cannot be sure that enough attention has been devoted to it to absorb the content. In this sense, for complex context-dependent information, the medium $i$ s the message. And the most powerful such medium for verifying the intentions of another is direct F2F contact.

\subsection{Screening and socialisation}

Even if we admit, on the basis of the above argument, that F2F is an efficient technology of transacting, it is nonetheless very costly, not least because it is time consuming. We do not have the luxury of F2F encounters with the entire world, so need to screen out the people with whom we want to interact. How do we identify such people? One way is formal screening procedures - examination and certification. Another is the development of informal networks, in which members of the network develop and share a pool of knowledge about members' competence.

Social and professional networks of this type often - although not always - require F2F contact. One reason is that they are necessarily based on individuals losing their anonymity; a member of the group is continually judging other members of the group, being judged, and sharing judgements with members of the group. In some internationalised professions - such as academia - this does not always require co-location, although is certainly reinforced by F2F in 
the conference circuit. In other activities these information networks can only be maintained within a restricted geographical area. In such fields as fashion, public relations, and many of the arts (including cinema, television, and radio) there are international networks "at the top," but in the middle of these professions networks are highly localised, change rapidly, and information used by members to stay in the loop is highly context-dependent. In parts of the financial services and high technology industries, local networks intersect with long-distance contact systems. In almost anything relating to business-government relations, networks have a strongly national and regional cast.

The screening of network members and potential partners is complex because much of what is most valuable about partners is their tacit knowledge. Much of such knowledge can only be successfully communicated as metaphor (Nisbet, 1969), whose meanings are highly culture and context-dependent (Lakoff and Johnson, 1980). Polanyi (1966:4) argued that tacit and metaphorical knowledge is deeply embedded in specific contexts. Thus, potential partners need to 'know' each other, or have a broad common background, acquired through socialisation. Sociological theory refers to socialization as the production of the individual as a social being who develops specific capacities to signal to others that she belongs to a certain world, and hence elicits from others the recognition of belonging. ${ }^{2}$ Individuals learn to share the "codes" which show that they have certain criteria of judgement, which in turn signal to others that they belong to the same social world (Coleman, 1990). This gives them the means to become members of structured milieux, to get "in the loop." Socialisation is inevitably achieved in large measure through face-to-face contact, from family, schooling, and the social environment in one's community and workplaces.

\footnotetext{
${ }^{2}$ The concept of socialization belongs upstream of economists' notions of human capital, screening and selection, because it is concerned with generation of initial capacities for action and discrimination, not merely their rational deployment. See Akerlof and Kranton (2000) for models of the economics of group identity.
} 
Notice, then, that F2F performs its screening role at two timescales in the economic process: in the long-run, by socializing people; in the short-run, by permitting potential collaborators to evaluate others' performance in professional groups and networks.

\section{4 "Rush" and the motivation that comes from F2F contact}

The final row of Table 1 shows another dimension of the incentive effects of F2F contact, which goes beyond verbal or visual communication. F2F communication does not derive its richness and power merely from allowing us to see each other's faces and to detect the intended and unintended messages that can be sent by such visual contact. As noted, according to Goffman (1959), F2F communication is a performance, a means to information production and not merely to more efficient exchange. In this performance, speech, intentions, role-playing and a specific context all come together to raise the quantity and quality of information which can be transmitted. Moreover, performance raises effort by stimulating imitation and competition. Psychologists have shown that the search for pleasure is a powerful motivating force in behavior, and certain kinds of pleasure are linked to pride of status and position: we imitate others, try to do better than them and derive pleasure from succeeding at so doing. When we make an effort, and are on the route to success, there is a bio-physical "rush" that pushes us forward. However, all pleasure quickly recedes as it blends into the preceding "normal" state, and it is only by once again changing this state that pleasure is found again. The search for such pride of status and position is thus a strong motivation which must be continuously renewed (Scitovsky, 1976). F2F contact provides the strongest, most embodied signals of such desire and can generate the rush that pushes us to make greater and better efforts. It is thus no surprise that even with the sophisticated computer monitoring that can be carried out on employee performance today, very few workplaces -- which are essentially centers of F2F contact -- have disappeared. It is not just 
that it is easier to monitor employees when they are present, it is also that such presence is motivating, because it contributes to desire, imitation, and competition, and the fear of shame from failure (Scitovsky, 1976; Kahneman, et al, 1998).

\section{WHY PEOPLE ENGAGE IN F2F: TWO MODELS}

With these basic properties of F2F contact in mind, we now propose two analytical models of how F2F improves the coordination of economic agents. In the first, F2F overcomes incentive problems in the formation of working partnerships; in the second, it allows actors to evaluate others' qualities and leads to the formation of "in groups" that support more efficient partnering and increased motivation. These models begin the task of developing a microeconomic theory of F2F. They both yield the result that productivity is raised by F2F contact.

\subsection{Incentives in joint projects.}

Game theoretic analysis provides a way of drawing out some of the incentive issues that arise when information is fluid and actions are not observable. To illustrate, suppose that two people are considering undertaking a joint project, but they are uncertain about its ultimate value or quality. All they know, initially, is that the project is either good, yielding final payoff A, or bad, yielding zero; they both attach the same prior probability, $\rho$, to the project being good. The game has two stages. The first involves acquisition of information about the quality of the project, and the second involves information sharing, deciding whether or not to undertake the project, and project implementation. What are the incentives to acquire information or to freeride, and how might they be improved by F2F contact?

At the first stage the two individuals undertake research independently and obtain a signal of whether the project is good or bad. The signal obtained by player $i$ may be favorable, $g_{i}$, or 
unfavorable, $b_{i}$. However, the signals are not accurate - a good project can send out a signal that it is bad, and vice versa. By expending effort, $e_{i}$, each player $(i=1,2)$ can improve the quality of the signal received (details are given in appendix 1).

At the second stage of the game players truthfully reveal their signals to each other. ${ }^{3}$ Using standard Bayesian techniques they use their combined information to compute the probability that the project is good; this probability is higher the more good signals have been received and the more effort has been expended, improving the quality of the signals. They then decide whether or not to proceed. Proceeding costs $C$ and yields payoff $A$ if the project turns out to be good, and zero otherwise; we assume $A \rho=C$, so (prior to research) the project yields zero expected surplus.

The incentives faced by individuals and the equilibrium outcomes are illustrated in Figure 1. The axes are the effort levels of the two players, and the lines OA and OB divide the space up into three regions. Between OA and OB effort levels are such that players will, at the second stage, choose to go ahead with the project only if they have both received good signals, $\left\{g_{1}, g_{2}\right\}$. However, below OB player 1 is putting in so little effort relative to player 2 (and hence 1's signal is so unreliable) that they proceed if 2 has a good signal and 1 a bad one $\left\{g_{2}, b_{1}\right\}$. Similarly, above OA they proceed with signals $\left\{g_{1}, b_{2}\right\}$. The curves labeled $\mathrm{EU}_{1}$ are expected utility indifference curves for player 1, increasing to the right, and kinked where they cross lines OA and $\mathrm{OB}$. The best response function for player 1 to each effort level $e_{2}$ is given by the bold solid lines, $e_{1}=R_{1}\left(e_{2}\right)$. We see that if $e_{2}$ is very low, then player 1 will ignore 2 's signal and put in a constant amount of effort (in the region to the left of OA). Conversely, if $e_{2}$ is high enough, player 1 will free-ride, putting in zero effort (in the region below OB). At intermediate levels of

\footnotetext{
${ }^{3}$ At this stage of the game there is no incentive for players to not reveal their true signal or the effort expended in obtaining the signal. A richer model might link the share of the project's surplus to effort, in which case there are incentives to misrepresent.
} 
$e_{2}$ player 1 puts in a positive level of effort, decreasing in $e_{2}$. Just as the solid bold lines are the best responses of player 1 to 2's effort levels, so the dashed bold lines (their reflection around the $45^{\circ}$ line) give the best responses of player 2 to 1 's effort levels.

As illustrated in Figure 1, this game has three Nash equilibria, labeled $E_{S}, E_{1}$ and $E_{2}$, occurring where the best response functions of the two players intersect. $E_{S}$ is symmetric, and involves both players putting in equal amounts of effort. $E_{1}$ and $E_{2}$ are equilibria where player 1 (respectively 2) exerts no effort; but given this, it is privately optimal for the other player to put in effort to the level illustrated. This free-riding means that little information is gathered, and at these equilibria more projects are undertaken than at $E_{S}$, the proportion of failing projects is larger, and aggregate returns lower. ${ }^{4}$

The multiplicity of equilibria reflects the incentives for individuals to free-ride in projects of this type. What can F2F do to select the symmetric equilibrium, where free-riding is reduced? F2F contact - a meeting between the players - can play two distinct roles. First, an F2F meeting prior to the start of the game may allow players to coordinate on this equilibrium. It is quite difficult to go into a meeting maintaining a commitment to put in no effort. This is partly because of the inherent simultaneity of the meeting: the two players are placed in a situation where neither has a mechanism to commit to making no effort. And it is partly because of the psychological effects of F2F contact; participants want to be highly esteemed by others and this is likely to be fostered by cooperation rather than conflict. With F2F it is thus difficult for one player to maintain the position that he will put in no effort and free ride on the other.

A second role that an F2F meeting can play derives from the fact that meetings are a relatively costly form of information exchange. Suppose that players can only exchange their

\footnotetext{
4 The game has a similar structure to 'chicken' in which two Californian kids drive towards each other. The last to swerve is the winner.
} 
information in a meeting. Attending the meeting has a real cost and, crucially, each player makes the decision of whether or not to attend on the basis of her own information: it is in the meeting that information is shared and the decision on whether or not to go ahead with the project is taken. How does this change the situation, as compared to costless information sharing? If the meeting cost is high enough then players who have done no research (as well as those who have received an unfavorable signal) will not find it worthwhile to attend the meeting. As a consequence, doing nothing is no longer privately profitable; each player has to pay a cost (that of attending the meeting) before obtaining the partner's information, and the cost is not worth paying given the original information.

In terms of Figure 1, there is a change in the shape of each player's indifference curves. Critically, below OB it is no longer worthwhile for player 1 to turn up to the meeting if his signal is bad. In this event there is no prospect of sharing surplus from the project, reducing $E U_{1}$ in the region below $\mathrm{OB}$, compared to above. This change in the shape of the $\mathrm{EU}_{1}$ indifference curves means that the best response function $R\left(e_{2}\right)$ is extended to the right from point $a$. Extending it sufficiently far, point $\mathrm{E}_{1}$ (and similarly $\mathrm{E}_{2}$ ) cease to be equilibria. The best response functions now have a single intersection at $E_{S}$ where both players have positive effort levels. The meeting therefore reduces the set of equilibria to the unique one at which both players make an effort.

This analysis, while highly stylized, formalizes two different possible roles that F2F meetings may have. One is as a form of preplay communication to coordinate on one of the possible equilibria. The other is as a way of increasing the cost of free-riding; a player who makes no effort will not find it worthwhile to attend the meeting, and so cannot make a positive return from the project. ${ }^{5}$

\footnotetext{
${ }^{5}$ Notice that this meeting is about information sharing, not about collective decision taking. In the latter context
} 


\subsection{The formation of in-groups: getting into the loop.}

We argued in section 2.3 that prior screening or socialization of potential partners is important. In many contexts this can be provided by formal certification and institutionalised screening mechanism, such as professional examinations. However, in other contexts particularly in creative activities where ability is hard to formally assess and where performance criteria cannot be codified and institutionalised - such formal techniques may not be very useful. Instead informal networks -- being 'in the loop' or in the 'in-group' -- may take their place as screening mechanisms.

What is the informational basis of such a group? Where ex ante screening and certification of individuals' ability or effort is not possible there has to be open, although not necessarily costless, membership to all. However, once in, members cease to be anonymous, knowing who is in the group, observing the performance of members, and in turn being observed by other members. This information is used to maintain the quality of the group. At its simplest, a record of failure is used as the basis for expulsion from the group. Group members are therefore continually judging and being judged, and know exactly who is 'in' and who is 'out'.

If an in-group of this type forms it will have a number of characteristics. First, it will contain a higher than average proportion of able people; high ability people have a higher probability of undertaking successful projects, so are more likely to survive as members of the group. Second, members of the group will (conditional on their ability) have higher earnings than outsiders, because they are matching with (on average) higher quality people. Third, members of the group will work harder than outsiders; the earnings differential creates an incentive to stay in the group, and the probability of staying in is increased by hard work. Finally, although initial access to the group is open to all, there may be an entry cost, perhaps in 
the form of time and effort to become known as deserving to belong to the group. Even if this is the same for people of all abilities it will have a greater deterrent effect for the less able because their income gain from being in the group is less. This is a further self-selection mechanism that reinforces the ability composition of the in-group relative to outsiders. ${ }^{6}$

To model this, suppose that there is a population of size one, with exogenous death and birth rate of $\delta$ per period. The population contains two types of individual, high ability and low ability, subscripted by $H$ and $L$, and the proportion of high ability in the population is $\bar{\mu}$. The size of the in-group is endogenously determined and denoted $\varphi$. The proportion of this group that is of high ability (also endogenous) is denoted $\mu^{I}$, while the proportion of outsiders that are high ability is $\mu^{\mathrm{O}}$, so $\bar{\mu}=\mu^{I} \phi+\mu^{O}(1-\phi)$ where we use superscripts $I$ and $O$ to denote variables for insiders and outsiders respectively.

In each time period all individuals match into pairs to undertake a project. Matching takes place within each group, but is otherwise random. The success or failure of a project depends on the ability of the two partners and the effort they put in, so the probabilities of success for projects with two high ability partners, a high ability partner and a low ability partner, or two low ability partners takes the following forms, for $i=\mathrm{O}$, I:

$$
\begin{aligned}
& \pi_{H H}^{i}=\rho_{H H}+f\left(e_{H}^{i}\right)+f\left(e_{H}^{i}\right), \\
& \pi_{H L}^{i}=\rho_{H L}+f\left(e_{H}^{i}\right)+f\left(e_{L}^{i}\right), \\
& \pi_{L L}^{i}=\rho_{L L}+f\left(e_{L}^{i}\right)+f\left(e_{L}^{i}\right)
\end{aligned}
$$

These probabilities depend on an exogenous component, $\rho_{H H}>\rho_{H L}>\rho_{L L}$, and on the effort of the individuals. We shall assume $\rho_{H H}-\rho_{H L}=\rho_{H L}-\rho_{L L}$, so that pairing with a high ability individual

\footnotetext{
6 The model lies, in broad terms, in the class of models of neighborhood formation - interactions occur between individuals in endogenously formed groups. Such models are surveyed by Durlauf (2003). The spatial aspect of the present model derives from knowledge flows within a spatially concentrated group, the membership of which is determined primarily by ejection due to failing projects.
} 
is as valuable for a low ability individual as it is for someone of high ability. ${ }^{7}$ An individual's effort is denoted $e_{H}^{I}$ for a high ability person inside the group, etc, and affects probability through an increasing concave function, $f($ ). Thus, a project is more likely to be successful if undertaken by high ability and harder working individuals.

If a project undertaken by members of the in-group fails, then both the participants in the project are ejected from the group with probability $\gamma .{ }^{8}$ Since the probability of failing depends on one's partner, and partners are selected randomly from members of the group, the ejection probabilities for high and low ability people, $\eta_{H}$ and $\eta_{L}$ are given by,

$$
\begin{aligned}
& \eta_{H}=\gamma\left[\left(1-\pi_{H H}^{i}\right) \mu^{I}+\left(1-\pi_{H L}^{i}\right)\left(1-\mu^{I}\right)\right] \\
& \eta_{L}=\gamma\left[\left(1-\pi_{H L}^{i}\right) \mu^{I}+\left(1-\pi_{L L}^{i}\right)\left(1-\mu^{I}\right)\right]
\end{aligned}
$$

Thus, the probability of an individual in the group matching with a high ability person is $\mu^{I}$; a partnership with two high ability individuals fails with probability $\left(1-\pi_{H H}^{i}\right)$ and a partnership with one high and one low ability individual fails with probability $\left(1-\pi_{H L}^{i}\right)$, etc.

The size and skill composition of the in-group can now be determined. The number of able people in the in-group, $\phi \mu^{I}$, evolves according to differential equation

$$
d\left(\phi \mu^{I}\right) / d t=\delta \bar{\mu} \lambda_{H}-\left(\eta_{H}+\delta\right) \phi \mu^{I}
$$

The first term is the flow of able people going into the group. This consists of births, $\delta$, proportion $\bar{\mu}$ of whom are able, and proportion $\lambda_{\mathrm{H}}$ of whom choose to enter the group (this proportion may be unity, and is discussed below). The second term is the number of high ability people who are ejected plus the number who die. Similarly, for low ability people,

\footnotetext{
${ }^{7}$ A good match has the same effect on probability for high and low ability people. Adding super-modularity would reinforce results that follow, while sufficient sub-modularity could reverse them.

8 This ejection probability is exogenous. In a more complex model it might depend on the full history of
} 


$$
d\left(\phi\left(1-\mu^{I}\right)\right) / d t=\delta(1-\bar{\mu}) \lambda_{L}-\left(\eta_{L}+\delta\right) \phi\left(1-\mu^{I}\right)
$$

In steady state these expressions are zero, giving the numbers of high ability and low people in the in-group, $\phi \mu^{I}$ and $\phi\left(1-\mu^{I}\right)$, as:

$$
\phi \mu^{I}=\frac{\delta \bar{\mu} \lambda_{H}}{\eta_{H}+\delta}, \quad \phi\left(1-\mu^{I}\right)=\frac{\delta(1-\bar{\mu}) \lambda_{L}}{\eta_{L}+\delta}
$$

Equations (1) - (5) give the base case model. If we suppose that all individuals have the same effort levels $\left(e_{H}^{I}=e_{L}^{I}=e_{H}^{O}=e_{L}^{O}\right)$ and all members of the population start off in the group, $\lambda_{\mathrm{H}}=\lambda_{\mathrm{L}}=1$, then it is easy to show that the in-group is of higher average ability than outsiders, $\mu^{I}$ $>\mu^{O}$, simply because high ability people are less likely to be involved in failing projects and face ejection. The benefits from being in the group can be evaluated once we specify returns to project success or failure. Suppose then, that a successful project yields payoff $2 \alpha$, an unsuccessful one yields $2 \beta$, and the payoff is split equally between the two partners. The expected payoffs to a high and low ability individual inside or outside $(i=\mathrm{I}, \mathrm{O})$ are given by,

$$
\begin{aligned}
& u_{H}^{i}=\alpha\left[\pi_{H H}^{i} \mu^{i}+\pi_{H L}^{i}\left(1-\mu^{i}\right)\right]+\beta\left[\left(1-\pi_{H H}^{i}\right) \mu^{i}+\left(1-\pi_{H L}^{i}\right)\left(1-\mu^{i}\right)\right]-e_{H}^{i} \\
& u_{L}^{i}=\alpha\left[\pi_{H L}^{i} \mu^{i}+\pi_{L L}^{i}\left(1-\mu^{i}\right)\right]+\beta\left[\left(1-\pi_{H L}^{i}\right) \mu^{i}+\left(1-\pi_{L L}^{i}\right)\left(1-\mu^{i}\right)\right]-e_{L}^{i}
\end{aligned}
$$

where we subtract the cost of effort. The present values of payoffs are,

$$
\begin{gathered}
V_{H}^{O}=u_{H}^{O} / \delta, \quad V_{L}^{O}=u_{L}^{O} / \delta, \\
V_{H}^{I}=u_{H}^{O} / \delta+\left(u_{H}^{I}-u_{H}^{O}\right) /\left(\delta+\eta_{H}\right), \quad V_{L}^{I}=u_{L}^{O} / \delta+\left(u_{L}^{I}-u_{L}^{O}\right) /\left(\delta+\eta_{L}\right),
\end{gathered}
$$

Outsiders, in the first row of equation (7), simply get instantaneous utility discounted at rate $\delta$. Insiders (second row) get additional utility for as long as they stay in the group. Under our assumptions (and with effort levels and group entry probabilities the same for all individuals) the 
instantaneous gains to being in the group are the same for high and low ability individuals, so $u_{H}^{I}-u_{H}^{O}=u_{L}^{I}-u_{L}^{O}$. However, the present value of being in the in-group is greater for high ability than low ability individuals, $V_{H}^{I}-V_{H}^{O}>V_{L}^{I}-V_{L}^{O}$. The reason is simply that they expect the benefits of group membership to last longer, as they are less likely to be involved in a failing project and to be ejected $\left(\eta_{L}>\eta_{H}\right)$.

This result drives several amplification effects. Suppose that individuals choose the level of effort they put in to maximize present value payoffs (equation (7)). An increase in effort increases the probability of success, and this is particularly valuable for insiders as it reduces the probability of ejection (equations (2)). First order conditions give, for outsiders and insiders respectively,

$$
\begin{gathered}
(\alpha-\beta) f^{\prime}\left(e_{j}^{O}\right)=1, \quad j=H, L \\
{\left[\alpha-\beta+\gamma\left(V_{j}^{I}-V_{j}^{O}\right)\right] f^{\prime}\left(e_{j}^{I}\right)=1, \quad j=H, L}
\end{gathered}
$$

We see that insiders work harder than outsiders because they fear ejection from the group. This effort effect is greater for more able people because $V_{H}^{I}-V_{H}^{O}>V_{L}^{I}-V_{L}^{O}$, so has the effect of further refining the group - high ability people work harder, are more likely to succeed, and hence have a still higher probability of staying in the group.

Finally, what proportion of new entrants to the labor force initially enter the in-group or not -- how are $\lambda_{\mathrm{H}}$ and $\lambda_{\mathrm{L}}$ determined? We assume that all individuals can enter the group, but now add a cost to entry -- perhaps the cost of working in a more expensive city, or of time invested in building initial contacts with the group. We model this as a fixed $\operatorname{cost} c$ that varies across individuals. Indexing members of the population by $z$, the cost takes the form, $c=\bar{c}+\widetilde{c} z$, $z \in[0,1]$. The proportions of high and low ability individuals who initially enter the in-group are 
obtained by finding the marginal entrant for whom the fixed cost equals the expected premium to being in the group, so:

$$
\lambda_{H}=\left[V_{H}^{I}-V_{H}^{O}-\bar{c}\right] / \widetilde{c}, \quad \lambda_{L}=\left[V_{L}^{I}-V_{L}^{O}-\bar{c}\right] / \widetilde{c}
$$

Once again, we see that the inequality $V_{H}^{I}-V_{H}^{O}>V_{L}^{I}-V_{L}^{O}$ causes a higher proportion of high ability than of low ability to enter the group initially. Entry costs therefore act as a self-selection mechanism, further increasing the ability gap between insiders and outsiders.

The results that we have outlined can be usefully summarized by a numerical example, given in table 2. The first column is the base case. Using parameters give in the appendix and an ejection probability of $0.8 \%$, the 'in-group' accounts for $18.4 \%$ of the population. It contains a substantially higher proportion of able people than the population at large, and yields its members higher present value utility than is received by outsiders. This effect is greater for high than for low ability individuals, $V_{H}^{I}-V_{H}^{O}>V_{L}^{I}-V_{L}^{O}$. Remaining columns allow for endogenous choice of effort and costs of entry to the group. If effort is endogenous people in the group work harder than outsiders and, since $V_{H}^{I}-V_{H}^{O}>V_{L}^{I}-V_{L}^{O}$, high ability group members put in more effort than low ability ones. The effect is to increase group size as failure probabilities are reduced, and to increase the proportion of the in-group that is high ability, $\mu^{I}$. Column 3 gives the effect of a cost of entering the group. Although this cost is the same for high and low ability people the return to being in the group is greater for high ability people. Thus, in this example, $81 \%$ of high ability people enter, compared to just $25 \%$ of low ability. The final column gives outcomes with endogenous effort and entry costs. This case compounds the previous effects, giving the highest value of $\mu^{I}$, the proportion of the in-group that is high ability. 
Table 2: Group formation: $\gamma=0.8$.

\begin{tabular}{|c|c|c|c|c|}
\hline & BASE & EFFORT & $\begin{array}{c}\text { COSTS OF } \\
\text { ENTRY }\end{array}$ & $\begin{array}{c}\text { EFFORT AND } \\
\text { ENTRY COSTS }\end{array}$ \\
\hline \hline$\varphi$ & 0.184 & 0.203 & 0.132 & 0.224 \\
\hline$\mu^{I}$ & 0.496 & 0.514 & 0.797 & 0.799 \\
\hline$\mu^{O}$ & 0.293 & 0.283 & 0.258 & 0.194 \\
\hline$V_{H}^{I}$ & 6.07 & 6.41 & 6.62 & 7.19 \\
\hline$V_{L}^{I}$ & 1.44 & 1.73 & 1.56 & 1.7 \\
\hline$V_{H}^{O}$ & 5.82 & 6.07 & 5.66 & 5.67 \\
\hline$V_{L}^{O}$ & 1.32 & 1.57 & 1.16 & 1.17 \\
\hline$\lambda_{\mathrm{H}}$ & 1 & 1 & 0.81 & 1 \\
\hline$\lambda_{\mathrm{L}}$ & 1 & 1 & 0.25 & 0.37 \\
\hline
\end{tabular}

Who are the gainers and who are the losers from this process? Rows 4 - 7 give the present value of individuals' utilities. ${ }^{9}$ If no group existed, all high ability individuals would have the same utility, as would all low ability individuals. Existence of the group creates a gap between insiders and outsiders, and this gap is larger for high-ability individuals than low ability, and is greater when effort is endogenous and entry costs cause selection of individuals initially entering the group. Outsiders are the big losers as refinement of group membership forces them to make worse matches. The gainers from the in-group are the high ability insiders. However, it is interesting to note that even these individuals do not want failure of a project to lead to ejection with probability 1 . Varying $\gamma$, it turns out that their utility is typically maximised at some value between zero and unity. Too low, and the group is not of high enough average quality; too high, and even high ability insiders face a significant probability of ejection.

This brings us back to our central points. F2F contact removes anonymity and allows people to judge and be judged. If you have been observed to fail then -- with probability $\gamma$-- you 
are branded an outsider, and group members will no longer seek to match with you. The magnitude of $\gamma$ is, in many activities, inherently spatial. In a faceless and anonymous world $\gamma=0$, and in-groups cannot form. F2F contact raises $\gamma$, creating the possibility of group formation. By removing anonymity F2F raises the probability of good, step-by-step iterative judgements about the abilities of others. An in-group that forms to generate and share this information improves the quality of matches made by workers, and also sharpens the incentives for individuals to succeed and increases the work effort of group members.

\section{F2F, BUZZ AND THE COORDINATION OF ECONOMIC ACTIVITIES}

\subsection{Buzz cities:}

Previous sections have highlighted the key features of F2F contact. It is a highly efficient technology of communication; a means of overcoming coordination and incentive problems in uncertain environments; a key element of the socialisation that in turn allows people to be candidates for membership of 'in-groups' and to stay in such groups; and a direct source of psychological motivation. The combined effects of these features we term 'buzz'. We speculate that there is a superadditivity in these effects, generating increasing returns for the people and the activities involved. Individuals in a buzz environment interact and cooperate with other highability people, are well placed to communicate complex ideas with them, and are highly motivated. To be able to reap these benefits in full almost invariably requires co-location, rather than occasional interludes of F2F contact. It is unsurprising that people in a buzz environment should be highly productive.

Amongst examples of this sort of interaction are joint projects in science, engineering and research. A large literature demonstrates the existence of localized, industry-specific knowledge

9 Where entry costs are incurred values are reported for the median individual in the group. 
spillovers within the science- and technology-based industries (Acz, 2002). Networks of firms and industries clustered within regions interact more heavily with co-located university-based scientists than with those in other regions (Darby and Zucker, 2002). This is associated with higher rates of commercialization than at long distances. Moreover, the various benefits of F2F that are established through long periods of colocation are durable: they have been shown to manifest themselves amongst people who then move away but continue to work together,and are much stronger than the contacts between long-distance partners (Breschi and Lissoni, 2003).

In many buzz cities there is also cross-fertilization between sectorally-specialized networks. High technology and government have close interactions, for example, and this is why Washington DC has become a major high-technology region. Design and entertainment/ communications have strong crossover effects in their development of content, and this is why places such as NY, LA, London and Paris concentrate them together (Pratt, 2002; Scott, 2003). Higher education, finance and government are a powerful nexus of ideas and contact networks for the socialization of elites and the coordination of their joint projects. These various internetwork, highly dynamic and unplanned contact systems were alluded to by Jacobs (1969), in her intuition that urban diversity is central to certain kinds of economic creativity because of the specific advantages of unplanned and haphazard, inter-network contact. Co-location is especially important to these processes because it provides a low-cost way for new ideas and talent to make their way into existing activities, by facilitating access for newcomers and by lowering the costs of evaluation on the part of those already in the relevant loops. New relationships are hence made easier, cheaper and much more effective than they would be without co-location.

In diversified city economies, functional agglomerations consist of pieces of different sectors sharing common input structures and common clients (Puga and Duranton, 2001). Buzz cities, we suggest, derive their agglomerative force both from the classical network 
agglomeration efficiencies and from the inter-network, interactive knowledge and informationbased activities including: (a) creative and cultural functions (including industries linked to this, such as fashion, design and the arts); (b) finance and business services; (c) science, technology and high technology and research; ${ }^{10}$ and (d) power and influence (government, headquarters, trade associations, and international agencies), (Hall, 1998; Scott, 2001). These cities' attraction for talent and their efficiency in socializing individuals confer important advantages on their participants. Buzz cities continue to have such force today because they are the places where, more than ever; critical problems of coordination in the modern economy are resolved through F2F contact.

Paradoxically, buzz cities are often those we most closely associate with globalization, because they are important nodes of highly developed international business and culture networks, with high levels of international travel-and-meeting activity, and high concentrations of both high-skilled and low-skilled immigrants. They often host many multinational enterprises. The most globalized cities also seem to have the most localized buzz. This is not surprising in view of the analysis provided here. The highest levels of international business require insertion into locally-grounded government and political networks in order to function efficiently.

\subsection{Buzz and alternative modes of coordination:}

Buzz is an important, or even essential, part of the way in which some activities operate, while for other activities it is unimportant. Table 3 offers a tentative taxonomy of alternative ways in which activities can be coordinated, in order to illustrate environments in which buzz is most important. The two dimensions by which activities are characterized are the kind of

\footnotetext{
${ }^{10}$ Though, as Florida (2002) points out, there is a detailed geography of creative workers within metropolitan areas. People in the fashion, design, government and finance sectors tend to inhabit different parts of the metropolitan space from those in science and engineering.
} 
knowledge on which they are dependent, and the fluidity of the environment in which they operate.

Table 3: MODES OF COORDINATION (Proximity requirement in italics)

\begin{tabular}{|c|c|c|c|}
\hline \multirow{3}{*}{$\begin{array}{l}\text { Environment of } \\
\text { Coordination: }\end{array}$} & \multicolumn{3}{|c|}{ Knowledge used in coordination } \\
\hline & \multicolumn{2}{|c|}{ SPECIALISED/ PRIVATE } & \multirow{2}{*}{$\begin{array}{l}\text { UBIQUITOUS/ } \\
\text { TRANSPARENT }\end{array}$} \\
\hline & TACIT & CODIFIED & \\
\hline STABLE & $\begin{array}{l}\text { Bureaucracy/ firms. } \\
\text { Specialised networks } \\
\text { for search/ matching. } \\
(H I G H) \\
\text { Financial services }\end{array}$ & $\begin{array}{l}\text { Bureaucracy/ firms } \\
\text { ( } L O W) \\
\text { Car industry (mass } \\
\text { production). }\end{array}$ & $\begin{array}{l}\text { Markets. }(L O W) \\
\text { Basic manufactured } \\
\text { inputs or services }\end{array}$ \\
\hline FLUID & $\begin{array}{l}\text { Buzz }(H I G H) \\
\text { Culture, politics, arts, } \\
\text { academia, new } \\
\text { technologies, } \\
\text { advanced finance }\end{array}$ & $\begin{array}{l}\text { Organized networks } \\
\text { for search/matching. } \\
(M E D I U M) \\
\text { Aerospace, } \\
\text { pharmaceuticals. }\end{array}$ & $\begin{array}{l}\text { Markets. ( } L O W) \\
\text { Commodities (eg oil) }\end{array}$ \\
\hline
\end{tabular}

In the right hand column are activities for which information is readily available/ observable, such as production and trade in basic manufactures and commodities. Markets are the main mode through which such activities are coordinated. The knowledge requirement of such activities is not a force for clustering - the proximity requirement is low.

Other activities are more dependent on specialist or private information, sometimes codified, and sometimes tacit. The middle column gives cases where the information can be codified, eg in well-defined engineering or chemical blueprints. Such activities are frequently internalized within firms or bureaucracies. The reasons for this have been extensively analyzed in the literature on the boundaries of the firm (Holmstrom and Roberts 1998). For example, intangible assets such as proprietary knowledge, reputation or good-will can be dissipated if traded through arms length transactions between firms. Internalization within an organization 
does not necessarily imply a high spatial proximity requirement.

Where information is largely codified but the environment is subject to significant fluctuation there may also be organized networks to facilitate search and matching of partners. This may create pressures for agglomeration due to the transactions costs associated with managing the input-output relations designed to cope with fluctuations in the environment. F2F contact is likely to be an important element of coordination, of both the market and contractual relations in the organized project system at hand. But the nature of F2F contact in this case is fundamentally different from the F2Fwhich is used in finding partners. Instead, such F2F is about monitoring the project organization, where the partners and the purposes of the collaboration (its intended outputs) are already defined. Such monitoring may require the rapidfire interaction and parallel processing of F2F, but it rarely involves the incentive problems of joint project formation or the complex processes of getting into loops which are associated with co-location. Under some circumstances it can therefore be carried out through occasional longdistance travel. Large-scale technology development projects, as in the aerospace or pharmaceuticals industries, are an example of this use of F2F without co-location.

The left-hand column gives cases where knowledge is tacit and is typically embodied in highly skilled workers. The need to communicate this knowledge creates a high proximity requirement. All this is amplified if the knowledge is fluid or the environment uncertain, as in the bottom left hand corner. This is the environment where buzz comes to the fore, because the uncertainty concerns not only the content of relevant information, but the purposes to which it will be put and the people who will be involved in using it.

\section{THE FUTURE OF F2F CONTACT AND COLOCATION}

The emphasis on F2F might seem paradoxical to some, since the advent of broad-band 
internet communications would appear, finally, to provide us the means to avoid F2F contact. The internet has enabled certain kinds of complex communication to occur at a distance which were previously constrained by proximity, and some have gone so far as to claim that this is leading to the "death of distance" (Cairncross, 2001).

The reality is certainly more complicated than this, however. The history of economic geography suggests a continuing tension between two opposing forces. On the one hand, there is ongoing transformation of complex and unfamiliar coordination tasks into routine activities that can be successfully accomplished at remote but cheaper locations. This is reflected in the codification of information, stabilization of meanings, and the reduction of incentive problems (opening up the possibility of more complete contracting), so that less F2F contact is needed. Its principal geographical consequence is the tendency towards deagglomeration or dispersion of production. On the other hand, bursts of innovations create new activities which can only initially be carried out via complex and unfamiliar coordination tasks. At any given moment, these two opposing forces combine in different ways, according to the activity at hand. The borderline between those activities which are amenable to relocation at a distance due to reduction in the cost and complexity of their associated transactions, and the new complex activities which require F2F and other forms of geographical proximity, is in constant evolution. New technologies may facilitate dispersion of production, but they also destabilize activities, creating uncertainty, research questions, and unknown opportunities. This is an environment in which information is rapidly changing and knowledge is tacit, conducive to buzz. It leads to a prediction that though the precise mix of activities involving F2F and co-location will change, they will constitute an important set of such activities well into the future, and will continue to generate agglomeration of highly-skilled individuals, firms, and bureaucracies in high-cost urban centers. 


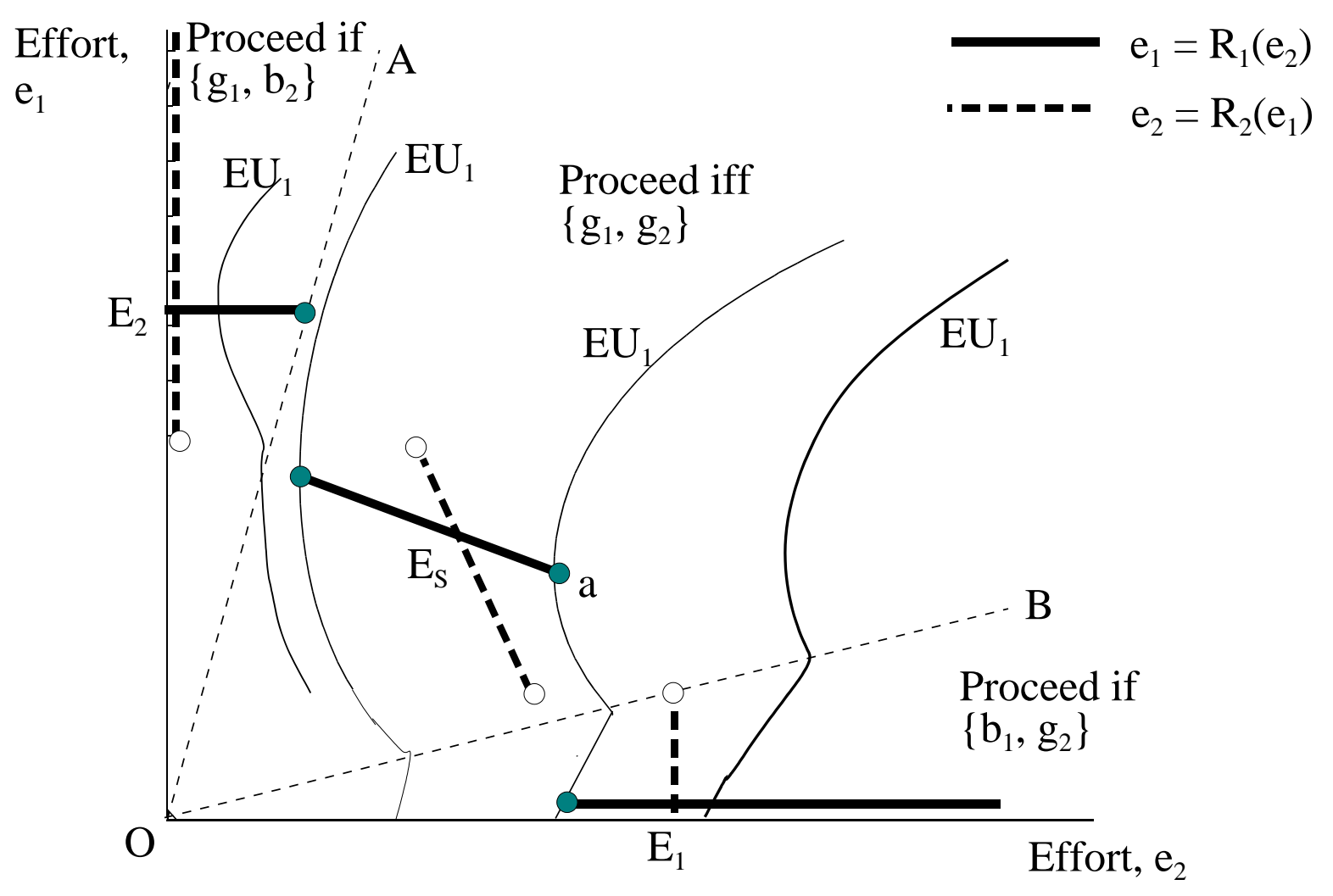

Figure 1: Equilibria in a game of information acquisition and sharing 


\section{Appendix 1:}

Payoffs are expected monetary gains minus $e_{i}$. A good project sends out signal that it is good with probability $\gamma$, and a false signal with probability $1-\gamma$. A bad project sends out a false signal (that it is good) with probability $\beta_{i}$, and the true signal with probability $1-\beta_{i}$, where $\beta_{i}=\left(\gamma^{-2}+\right.$ $\left.e_{i}\right)^{-0.5}$. Thus, if no effort is expended, $\beta_{i}=\gamma$.

Parameter values: $A=150, C=50, \rho=1 / 3, \gamma=0.8$.

Probabilities are all computed by Bayes theorem and figure 1 is computed in GAUSS.

\section{Appendix 2:}

Parameter values: $\bar{\mu}=0.33, \delta=0.1, \alpha=1, \beta=0, \gamma=0.8, \rho_{H H}=0.9, \rho_{H L}=0.45, \rho_{L L}=0$, $\bar{c}=0.15, \widetilde{c}=1$. Effort function: $f(e)=s e^{0.5}, s=0.2$.

\section{References:}

Acz, Z. 2002, Innovation and the Economy of Cities. Cheltenham: Edward Elgar.

Akerlof, G.A and R.E. Kranton, 2000, 'Economics and Identity', Quarterly Journal of Economics, CXV, 715-753.

Austin, JL, 1962. How to Do Things with Words. Oxford: Clarendon Press.

Bateson, G. 1973, Steps Toward an Ecology of Mind, London: Paladin Press.

Becattini, G, 2000, Il Distretto Industriale: Un Nuovo Modo di Interpretare il Cambiamento Economico. Turin: Rosenberg \& Sellier.

Breschi, S and Lissoni, M 2003, "Mobility and Social Networks: Localised Knowledge Spillovers Revisited.” Milan: University Bocconi, CESPRI Working Paper no. 142.

Cairncross, F, 2001, 'The death of distance 2.0; how the communications revolution will change our lives', Harvard Business School Press, Cambridge.

Coleman, JS, 1990, Foundations of Social Theory. Cambridge, MA: Harvard/ Belknap.

Crozier, M. 1964. The Bureaucratic Phenomenon. Chicago: University of Chicago Press.

Csikszentmihalyi, M, 1996, Creativity: Flow and the Psychology of Discovery and Invention. New York: Harper Collins.

Darby, M. and Zucker, L.G., 2002, “Growing by leaps and inches: creative destruction, real cost reduction, and inching up.” Cambridge, MA: NBER Working Paper no. 8947.

DeVries, J, 1984, European Urbanization 1500-1800, Cambridge, MA: Harvard University 
Press.

Dumais,G; Ellison, G; and Glaeser, E, 1997. 'Geographic Concentration as a Dynamic Process.' Cambridge, MA: NBER Working Paper no. 6270.

Durlauf, S.N. 2003 'Neighborhood Effects', forthcoming in 'Handbook of Regional and Urban Economics' eds J.V. Henderson and J.-F. Thisse, North-Holland, Amsterdam.

Feldman, M and Audretsch, D, 1999, 'Innovation in Cities: Science-based Diversity, Specialization, and Localized Competition,' European Economic Review 43: 409-29.

Florida, R, 2002, The Rise of the Creative Class, New York: Basic Books.

Fujita, M., P. Krugman and A.J. Venables, 1999 'The spatial economy; cities, regions and international trade', MIT press Cambridge MA.

Gambetta, D., ed, 1988. Trust. Oxford: Oxford University Press.

Garfinkel, H. 1987. Studies in Ethnomethodology. Oxford: Blackwell.

Gaspar, J. and E.L. Glaeser, 1998, 'Information technology and the future of cities', Journal of Urban Economics, 43, 136-156.

Glaeser, E.L. 1999. 'Learning in cities', Journal of Urban Economics, 46, 254-277.

Goffman, E. 1959.The Presentation of Self in Everyday Life. New York: Doubleday.

Goffman, E. 1982. Interaction Rituals: Essays on Face-to-Face Behavior. New York: Pantheon Books.

Gordon, I.R. and McCann, P, 2000, "Industrial Clusters: Complexes, Agglomeration, and/or Social Networks?" Urban Studies 37: 513-532.

Granovetter, M. 1995. Getting a job: a study in contacts and careers. Chicago: University of Chicago Press.

Hall, P., 1998, Cities in Civilization, Oxford: Blackwell.

Hanson, G, 2000, "Firms, Workers and the Geographic Concentration of Economic Activity." in: Clark, G; Gertler, M; and Feldman, M, eds, The Oxford Handbook of Economic Geography, Oxford: OUP, 477-494.

Holmstrom. B. and J. Roberts. 1998. 'The boundaries of the firm revisited', Journal of Economic Perspectives, 12, 73-94.

Husserl, E., 1968. The Ideas of Phenomenology. The Hague: Nijhoff. Jacobs, J, 1969. The Economy of Cities. New York: Random House.

Jaffe, A; Trachtenberg, M and Henderson, R, 1993, 'Geographic Localization of Knowledge Spillovers as Evidenced by Patent Citations,' Quarterly Journal of Economics 63: 577- 
598.

Jayet, H, 1983, 'Chômer plus souvent en région urbaine, plus longtemps en région rurale,' Economie et Statistique 153: 47-57.

Kahneman, D; Diener, E; Schwartz, N. 1998. Understanding well-being: Scientific Perspectives on Enjoyment and Suffering. New York: Russell Sage Foundation.

Kim, S. 1995, 'Expansion of Markets and the Geographic Distribution of Economic Activities: Trends in US Manufacturing Structure, 1860-1987,' Quarterly Journal of Economics 110: 881-908.

Kim, S, 2002, "The reconstruction of the American urban landscape in the twentieth century," Cambridge, MA: NBER Working Paper 8857.

Klein, B. and Leffler, K, 1995, 'The role of market forces in assuring contractual performance,' in Williamson, O and Masten, S, eds, Transaction Costs Economics, vol. 1: Theory and Concepts. London: Elgar, 181-207.

Lakoff, G. and Johnson, M. 1980. Metaphors We Live By. Chicago: University of Chicago Press.

Leamer, E and Storper, M, 2001, 'The Economic Geography of the Internet Age.' Journal of International Business Studies (December), and NBER Working Paper no. W8450.

Lorenz, E. 1992. 'Trust and the Theory of Industrial Districts.' in M. Storper and AJ Scott, eds, Pathways to Industrialization and Regional Development, London: Routledge.

Marshall, A, 1919. Principles of economics, London: Macmillan, (8th ed.).

Mehrabian, A, 1981, Silent Messages: Implicit Communications of Emotions and Attitudes. Belmont, CA: Wadsworth.

Nisbet, R. 1969. Social Change and History: Aspects of the Western Theory of Development. Oxford: Oxford University Press.

Nohria, N and Eccles, R, 1992, Networks and Organizations: Structure, Form and Action. Boston: Harvard Business School Press.

Nonaka, I. 1994. 'A Dynamic Theory of Organisational Knowledge Creation.' Organization Science 5,1: 14-37.

Osborne, M.J., J.S. Rosenthal and M.A. Turner 2000. 'Meetings with costly participation', American Economic Review, 90: 927-943

Polanyi, M. 1966. The Tacit Dimension. London: Routledge.

Porter, ME, 2001, "Clusters of innovation: regional foundations of competitiveness." 
Washington, DC: US Council on Competitiveness

Pratt, A.C. 2002, "Firm Boundaries? The organization of new media production in SF 1996-98." London: LSE Dept of Geography, manuscript.

Puga, D and G. Duranton, (2001), 'From sectoral to functional specialisation', CEPR dp no 2971

Putnam, R. 2000. Bowling Alone; the Collapse and Revival of American Community. New York: Touchstone.

Rosenfeld, S, 1996. "United States: Business Clusters." IN: OECD, Networks of Enterprises and Local Development. Paris: Organisation for Economic Cooperation and Development, Territorial Development Service.

Rotemberg J.J. and G. Saloner 2000, 'Competition and human capital accumulation; a theory of inter-regional specialisation and trade', Regional Science and Urban Economics, 30, 373 404.

Scitovsky, T. 1976. The Joyless Economy: An Inquiry into Human Satisfaction and Consumer Dissatisfaction. New York: Oxford University Press.

Scott, AJ, 1988, Metropolis: From the Divison of Labor to Urban Form, Berkeley and Los Angeles: University of California Press.

Scott, AJ, ed, 2001, Global City Regions: Theory and Policy. Oxford: Oxford University Press. Searle, J. 1969. Speech Acts: An Essay in the Philosophy of Language. New York: Cambridge University Press.

Simmel, G. 1950, The Sociology of Georg Simmel. Glencoe, IL: The Free Press.

Storper, M. 1997. The Regional World: Territorial Development in a Global Economy. New York and London: The Guilford Press.

Storper, M and Walker, R, 1989, The Capitalist Imperative: Territory, Technology and Industrial Growth. Oxford: Blackwell.

Storper, M and Salais, R, 1987, Worlds of Production: the Action Frameworks of the Economy. Cambridge, MA: Harvard University Press.

Williamson, O. 1985. The Economic Institutions of Capitalism. New York: The Free Press. 


\section{CENTRE FOR ECONOMIC PERFORMANCE \\ Recent Discussion Papers}

597 Stephen Gibbons

Alan Manning

596 Paul Gregg

Maria Gutiérrez-

Domènech

Jane Waldfogel

595 Stephen Bond

Dietmar Harhoff

John Van Reenen

594 Andrew B. Bernard

Stephen Redding

Peter K. Schott

593 Anthony J. Venables

592 Sylvie Charlot

Gilles Duranton

591 Paul Willman

Alex Bryson

Rafael Gomez

590 Marco Manacorda

589 Alex Bryson

Rafael Gomez

588 Henry G. Overman

L. Alan Winters

587 Pierre-Philippe Combes Henry G. Overman

586 Henry G. Overman
The Incidence of UK Housing Benefit: Evidence from the 1990s Reforms

The Employment of Married Mothers in Great

Britain: 1974-2000

Investment, R\&D and Financial Constraints in Britain and Germany

Product Choice and Product Switching

Spatial Disparities in Developing Countries: Cities, Regions and International Trade

Communication Externalities in Cities

Why Do Voice Regimes Differ?

Child Labor and the Labor Supply of Other

Household Members: Evidence from 1920 America

Why Have Workers Stopped Joining Unions?

Trade Shocks and Industrial Location: the Impact of EEC Accession on the UK

The Spatial Distribution of Economic Activities in the European Union

Can We Learn Anything from Economic Geography Proper? 
585 A. B. Bernard

J. Bradford Jensen

P. K. Schott

584 A. B. Bernard

J. Bradford Jensen

P. K. Schott

583 S. Wood

S. Moore

582 T. Kirchmaier

581 C. Dougherty

$580 \quad$ S. Burgess

D. Mawson

579 S. Nickell

578 D. Marsden

$577 \quad$ S. Nickell

576 A. de Coulon

M. Piracha

575 H. Steedman

K. Wagner

J. Foreman

574 S. Gibbons

573 R. Griffith

S. Redding

H. Simpson
Falling Trade Costs, Heterogeneous Firms and Industry Dynamics

Survival of the Best Fit: Exposure to Low-Wage Countries and the (Uneven) Growth of U.S.

Manufacturing Plants

Reviewing the Statutory Union Recognition (ERA 1999)

Corporate Restructuring and Firm Performance of British and German Non-Financial Firms

Why Is the Rate of Return to Schooling Higher for Women than for Men?

Aggregate Growth and the Efficiency of Labour

Reallocation

Poverty and Worklessness in Britain

Renegotiating Performance: the Role of Performance Pay in Renegotiating the Effort Bargain

A Picture of European Unemployment: Success and Failure

Self-Selection and the Performance of Return

Migrants: the Source Country Perspective

The Impact on Firms of ICT Skill-Supply Strategies: An Anglo-German Comparison

The Costs of Urban Property Crime

Productivity Convergence and Foreign Ownership at the Establishment Level 